ARS

ano 15

n. 31 palavras-chave:

Alair Gomes; fotografia; arte contemporânea; Brasil - Estados Unidos: publicação de artista

keywords: Alair Gomes; photography; contemporary art; Brazil - United States; artists' magazines

1. Este artigo engloba os principais assuntos discutidos na dissertação de mestrado

"Ask me to send these photos to you": a produção artística de Alair Gomes no contexto norte-americano, concluída em 2016 no Programa de Pós- Graduação em Artes Visuais da ECA-USP. As imagens apresentadas aqui apenas ilustram de maneira sumária os trabalhos do fotógrafo e não configuram a organização e sequencialidade requeridas por Alair Gomes.

* Universidade de São Paulo [USP].

\section{André Pitol*}

\section{"Ask me to send these photos to you": a produção artística de Alair Gomes nos Estados Unidos'.}

\section{Ask me to send these photos to you": the artistic work of Alair Gomes in the United States.}

Antes de ser conhecida no Brasil, a produção fotográfica de Alair Gomes circulou nos anos 1970 e 1980 nos Estados Unidos, em publicações tanto do meio das artes quanto ligadas a uma homossociabilidade estadunidense, como são os casos das revistas Performance, Gay Sunshine, The Advocate e Advocate MEN, e do Artists Almanac. Este artigo analisa tal conjunto de trabalhos, apontando seus principais elementos visuais, como a montagem de múltiplas fotografias, e sinalizando o suporte impresso como um elemento-chave para a compreensão da poética do artista, especialmente a materialidade e a sequencialidade da imagem fotográfica na página impressa. Objetiva-se nesta análise incrementar as possibilidades interpretativas entre o fotógrafo e o cenário artístico contemporâneo, que até o momento permanece restrita ao aspecto homoerótico de sua obra.

Before it was known in Brasil, the photography works of Alair Gomes circulated during the 1970s and 1980s in the United States, both in publications of art and linked to the American homosociability, as it was the case of the magazines Performance, Gay Sunshine, The Advocate and Advocate MEN, and in the Artists Almanac. This article analyses the group of works, pointing out their main visual elements, like the assembly of multiple photographies, showing the printed support as the key element for the understanding of the artist poetic, more precisely the materiality and sequenciality of the photographic image on a printed page. The objective of this analysis is to increase the interpretations between the photographer and the contemporary artistic scene, which at the moment remains be connected exclusively to the homoerotism of its works. 
Conhecido principalmente por suas séries de fotografias de corpos masculinos, posando em diversas situações, como exercitando-se em aparelhos de ginástica nas praias de Ipanema, nas ruas próximas à orla da zona sul carioca, ou apenas nus, a produção artística de Alair Gomes não se restringe à temática homoerótica. A aproximação entre fotografia e sexualidade na produção do fotógrafo é parte da atuação construída por diversos atores do campo artístico, seja da crítica de arte, seja do meio acadêmico. Mediante exposições e pesquisas realizadas a partir dos anos 1990, as análises que focalizavam a linguagem fotográfica e a montagem sequencial e narrativa em seu trabalho - como nos textos de Walmyr Ayala, Frederico Morais e Roberto Pontual - foram sendo paulatinamente modificadas em direção a interpretações que enfatizam noções como homoerotismo, homoarte e voyeurismo - como nas pesquisas de João Luiz Vieira, Paulo Herkenhoff, Wilton Garcia e Alexandre Santos² ${ }^{2}$ Esse movimento gerou uma homogeneização temática sob a tese de se tratar de uma produção fundamentalmente homoerótica e, em última instância, ocasionou a invenção de um único Alair Gomes, um perfil de artista solitário e apartado do cenário artístico do Rio de Janeiro nos anos 1960 e 1970.

Toda essa construção discursiva, como hoje se sabe, foi paulatinamente estruturada em cima de uma imagem de fotografia homoerótica a despeito de uma pesquisa ampla sobre a produção do artista, mesmo com a justificativa de que esta parcela extremamente significativa da produção do fotógrafo se encontrasse dispersa. Fatores da ordem de produção, como a materialidade das imagens, da ordem de circulação e as escolhas de determinadas séries fotográficas para exposições individuais e coletivas, não foram até agora fortemente considerados. Estas informações, esquecidas ou negligenciadas, ajudariam a construir uma visão mais abrangente e menos fetichizada de Alair Gomes.

Como uma tentativa de atualizar a perspectiva apontada anteriormente, propõe-se aqui a análise de alguns trabalhos fotográficos que Alair Gomes publicou entre os anos de 1971 e 1987, nos Estados Unidos. Compõem este conjunto o ensaio The Balcony (a photo portfolio), publicado na revista Performance (1971) e a participação em Artists Almanac (1975), bem como a Carnival in Rio: a photo essay, publicado em 1979 na Gay Sunshine: Journal of Gay Liberation e, por fim, dois ensaios nas revistas The Advocate, um em 1983, e o outro em Advocate MEN, em 1987. Os cinco trabalhos apresentam um conjunto amplo de imagens realizadas pelo fotógrafo, sendo que algumas delas foram feitas desde, pelo menos, meados da década de 1960, como registros fotográficos de espetáculos teatrais e do carnaval de rua do Rio de Janeiro
104

André Pitol

"Ask me to send these photos

to you": a produção artística de Alair Gomes nos Estados Unidos.

2. Uma análise pormenorizada dessa discussão pode ser encontrada em Trabalho de Conclusão de Curso, Alair Gomes: Fotografia, crítica de arte e sexualidade (2013). Disponível em: <https://goo.gl/KqWBjD>. Acesso em: 20 fev. 2017. 
- principalmente de blocos como o Cacique de Ramos - e também mostram uma parte extensa de fotografias de corpos masculinos, andando pelas ruas, exercitando-se na orla, nas praias cariocas, ou em sessões no apartamento do fotógrafo transformado em estúdio.

Esses elementos são característicos dos trabalhos mais conhecidos de Alair Gomes - como as séries Sonatinas, Four Feet, The Course of the Sun, A Window in Rio e Beach Triptychs. Encontram-se neles o protagonismo da fotografia pensada como arte e a montagem de narrativas realizadas a partir da sequencialidade de múltiplas imagens fotográficas. Porém, para além disso, nota-se que a veiculação do material em revistas, jornais e no livro do artista reforçou os procedimentos característicos da produção artística dos anos 1960 e 1970, ou seja, o uso do suporte impresso como o lugar do trabalho de arte, sendo assim crucial para o entendimento de sua poética. A relação entre a montagem fotográfica e a organização das imagens em suportes impressos é o aspecto central deste texto.

A experiência singular que Alair Gomes deu ao suporte impresso como um lugar de veiculação da arte fez que considerasse a fotografia, como o próprio fotógrafo escreve, como um print-making médium. Essa expressão aponta para interesses que abarcam o campo gráfico e de comunicação de massa, bem como, pelo idioma utilizado, evidencia contatos com o contexto norte-americano, imprescindíveis no entendimento das condições de produção e circulação de sua fotografia.

Outra aproximação entre o aspecto gráfico, fotográfico e estadunidense na trajetória de Alair Gomes foi a relação profissional que ele estabeleceu com o designer Quentin Fiore, responsável por várias parcerias editoriais com o teórico da comunicação Marshall McLuhan, como o livro $O$ meio são as mensagens: um inventário de efeitos, publicado em 1969 no Brasil. Alair Gomes foi o responsável pelo acompanhamento de Fiore em sua vinda ao Brasil em novembro de 1969, para participar como jurado do Concurso Internacional de Cartaz sobre o Café, no Rio de Janeiro, e para realizar diversas conferências sobre os meios gráficos e a comunicação, muito provavelmente por conta do livro que fez juntamente com McLuhan, traduzido para o português por Décio Pignatari. O designer realizou uma palestra no auditório do Museu de Arte Moderna do Rio de Janeiro e

3. MAURICIO, Jayme. Quentin no Museu. Correio da Manhã, Rio de Janeiro, 19 nov. 1969 , Anexo, p. 3 outra no Instituto dos Arquitetos de São Paulo ${ }^{3}$ e este encontro entre o Alair Gomes e Quentin Fiore continuou em forma de correspondência durante muitos anos, sendo possível verificar nas mensagens enviadas pelos dois uma potente troca de pontos de vista sobre as possibilidades artísticas dos suportes impressos e a produção impressa em série da 
fotografia, temas que se aproximam das características dos trabalhos do fotógrafo publicados nos Estados Unidos.

Além do papel de cicerone que desempenhou com a vinda de Quentin Fiore ao Brasil, findando-se o ano de 1969, Alair Gomes publica na revista Cadernos Brasileiros uma resenha de Os meios de comunicação como extensões do homem, outro livro de Marshall McLuhan. Esta discussão - das artes e dos meios de comunicação -, que perpassa ainda autores decisivos da época, foi de grande importância para os debates acerca da arte, da mídia e da reprodutibilidade no campo artístico, tanto no exterior quanto no Brasil ${ }^{4}$. As contribuições de Alair Gomes acerca da relação entre a sua produção fotográfica e o suporte impresso conduzirão grande parte das análises apresentadas adiante. A reunião desse material oferece uma possibilidade importante de se retomar a investigação sobre o fotógrafo na busca de uma melhor compreensão de sua produção artística, assim como intencionando uma atualização histórica necessária sobre o lugar de Alair Gomes na cena cultural artística contemporânea.

Assim, a proposta encontra suas bases em uma leitura diferenciada sobre o fotógrafo, distanciando-se da presente perspectiva abordada na historiografia brasileira. Busca-se ampliar a identificação de sua fotografia com a imagem homoerótica e se destaca o fato de que sua produção envolveu variados elementos: a sequencialidade das imagens, a materialidade do suporte impresso e a circulação atingida na cena norte-americana, que possibilitou uma produção conectada às complexidades de seu espaço e tempo histórico.

\section{Fotografia e teatro no meio impresso norte-americano}

The Balcony (a photo portfolio) foi o primeiro trabalho fotográfico de Alair Gomes nos Estados Unidos. Ele foi publicado no primeiro número de Performance, em 1971, uma revista voltada para o meio teatral e editada pela Universidade de Nova Iorque (NYU).

As doze páginas que compõem o ensaio de Alair Gomes registram uma das apresentações da montagem brasileira da peça teatral O Balcão, escrita por Jean Genet, que permaneceu em cartaz por quase dois anos no Teatro Ruth Escobar, em São Paulo. A publicação do foto-ensaio em Performance está relacionada ao sucesso da peça no Brasil e ao anúncio de sua montagem em Nova Iorque ${ }^{5}$. O ensaio de Alair Gomes explora uma relação crucial entre a fotografia e o teatro, presente na proposta de O Balcão. Em primeiro lugar, a peça já contava com fotógrafos em seu roteiro, responsáveis pelos retratos dos
106

André Pitol

"Ask me to send these photos

to you": a produção artística de Alair Gomes nos Estados Unidos.

4. Cf. MAIA, Ana. Arte-veículo: intervenções na mídia de massa brasileira. Recife: Aplicação, 2015. Disponível em: <https://goo.gl/K2YoMH>. Acesso em: 24 nov. 2017.

5. Além da publicação em Performance, Ruth Escobar e Rofran Fernandes, assistente de direção de 0 Balcão, foram a Nova lorque para exibir o filme documentário sobre a peça realizado pelo cineasta José Agripino de Paula. SCHOENBACH, Peter. Rio and São Paulo Theatres in 1970: foreign dramaturgy. Latin America Theatre Review, Lawrence, v. 5, n. 1, p. 69-80, outono 1971. 
três personagens principais - o Bispo, o Juiz e o General. A relevância

6. MCLUHAN, Marshall. Os meios de comunicação como extensões do homem. São Paulo: Cultrix, 1969, p. 215.

7. WHITE. Edmund. Genet: uma biografia. Rio de Janeiro: Record, 2003. da fotografia como parte da peça fez que McLuhan apontasse que "a fotografia inspirou Genet em seu tema do mundo como um bordel, pois a fotografia é um Bordel Sem Paredes"6. Além disso, a fotografia estava intimamente relacionada com a concepção cênica da peça, a saber: na multiplicação de possíveis pontos de vistas dos espectadores interagirem com o palco e com os atores.

O cenário era o elemento-chave dessa relação da peça, sendo que tanto o roteiro quanto as indicações do próprio Genet sugeriam a necessidade de um ambiente cênico que deslizasse de um lado para o outro do palco $^{7}$. Essas recomendações não haviam sido cumpridas em outras montagens do espetáculo, como as que ocorreram em Londres (1957) e em Paris (1960), de modo que trouxeram inúmeras dificuldades para a sua execução. A montagem em São Paulo, por sua vez, atendeu com compromisso e potência criativa às recomendações em um esforço que fez que a versão brasileira ficasse internacionalmente reconhecida, especialmente nos Estados Unidos, país que já havia produzido uma montagem do espetáculo, no Circle in the Square Theatre de Nova Iorque, em março de 1960. Concebido pelo encenador argentino Victor Garcia e construído pelo arquiteto brasileiro Wladimir Pereira Cardoso, a cenografia de $O$ Balcão modificou a estrutura do Teatro Ruth Escobar com a destruição dos espaços da plateia do teatro e a abertura de um vão livre de 20 metros de altura. Neste foi construída uma estrutura cilíndrica de ferro, com múltiplas plataformas transparentes e passarelas móveis para os atores, além de pequenas gaiolas suspensas no espaço por cabos de aço.

Fig. 1

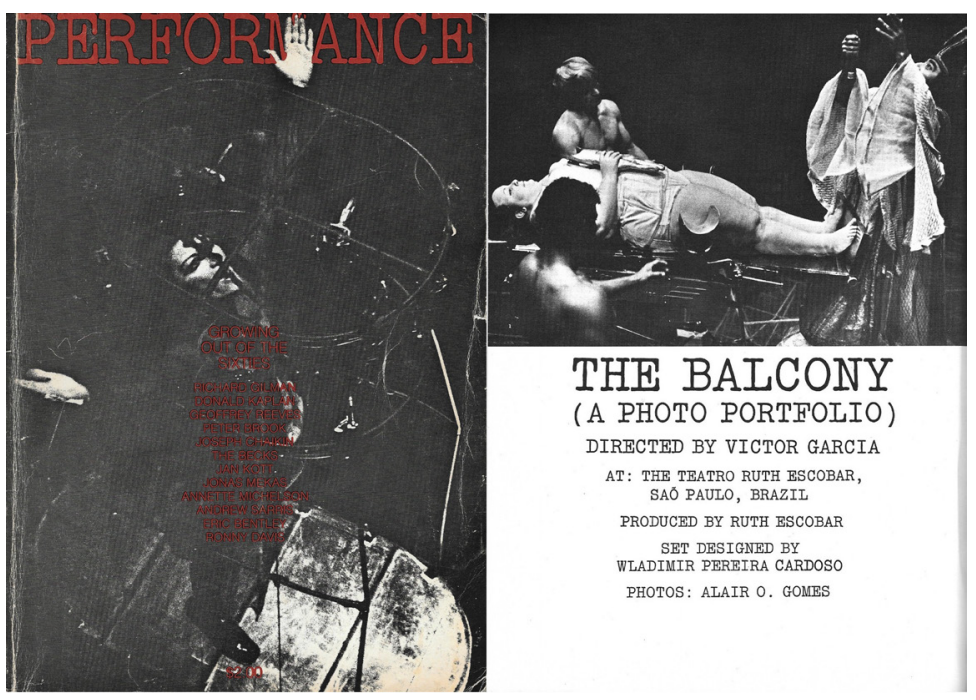




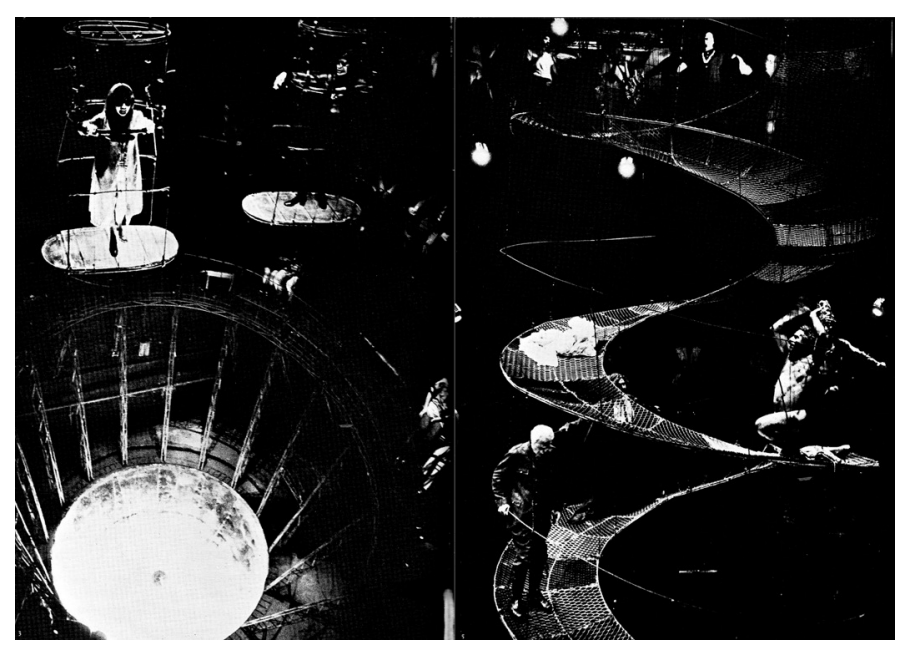

A cenografia criada subverteu as convenções determinadas pela cena frontal do teatro tradicional. A complexidade mecânica dos elementos cenográficos possibilitou uma grande exploração entre as áreas de atuação e do público, abrindo espaço para as novas relações de representação entre os atores, o espaço de atuação e os espectadores. A experimentação criada pela alteração do espaço cênico como um espaço de captação da imagem a partir de uma perspectiva não frontal ocasionou um deslocamento físico da posição do observador, ressignificando, com isso, toda a montagem narrativa dos possíveis registros fotográficos realizados sobre a peça. E, assim como o teatro modificou sua estrutura, a fotografia também alterou lugar privilegiado do observador.

No palco vertical, havia a apresentação de cenas que ocorriam simultaneamente. A estrutura móvel acionada a cada mudança de cena fazia que a plateia tivesse que se locomover de tempos em tempos, criando a cada momento uma nova perspectiva do que o espectador estava assistindo. A mudança constante da localização da plateia durante a apresentação, em função da alteração da mobilidade da estrutura cênica, permitiu a Alair Gomes incorporar a circularidade e a verticalidade do espaço cênico em suas imagens. As fotografias de The Balcony (a photo portfolio) evidenciavam esta mudança do lugar do fotógrafo como observador e apresentam vários elementos que construíram esta unidade poética entre a fotografia e o espaço teatral.

$\mathrm{O}$ ensaio de Alair Gomes assume o lugar do espectador, deslocando o ponto de vista da fotografia - a inclinação do ângulo da câmera, a organização dos elementos compositivos e a distância em relação aos objetos retratados - resultando em imagens compostas de tal maneira que os corpos permanecem oblíquos ao chão. Além dos pontos
108

André Pitol

"Ask me to send these photos

to you": a produção artística de Alair Gomes nos Estados Unidos.

Fig. 2

Alair Gomes, The Balcony (a photo portfolio), 1971. 
ARS de vista diagonais, a iluminação reforçava a perspectiva oblíqua de $O$ ano 15 Balcão, sendo que a principal parte das projeções de luz vinha do fosso

n. 31 do teatro, clareando o cenário de modo ascendente. A transparência das estruturas metálicas e das plataformas funcionava a fim de facilitar a observação das cenas, assim como resultava na criação de uma contraluz no ambiente, em uma série de contrastes de luzes e sombras que dinamizavam a percepção da plateia sobre o espetáculo. Assim, a narrativa de The Balcony (a photo portfolio) funcionou como uma síntese narrativa de $O$ Balcão, em uma montagem unificada pela sequência de páginas da revista. O contraste visual do foto-portfolio é reforçado pela materialidade das páginas de Performance e evidenciam o efeito de um ensaio fotográfico em um suporte impresso, fazendo que o ensaio ganhe um aspecto gráfico significativo.

Com a publicação de The Balcony, foi possível discutir a noção de ensaio fotográfico experimentada por Alair Gomes naquele período. A relação da fotografia com o meio teatral nos sugere que as investigações realizadas pelo autor levaram a fotografia a perpassar uma abordagem que a afastava de uma concepção essencialista de meio. $\mathrm{O}$ tratamento dado àquelas imagens, bem como a organização destas na montagem do ensaio, traz para The Balcony uma especificidade distante daquela do fotojornalismo tradicional. Juntas, estas características apontam para múltiplas possibilidades de construção de trabalhos com mais de uma imagem fotográfica. Essa familiaridade de Alair Gomes para com o uso da fotografia como ensaio construiu um retrato particular do cenário cultural de um espetáculo.

Já a complexa logística de execução da estrutura cenográfica nos Estados Unidos - juntamente com o fato de que os trezentos lugares da montagem em São Paulo eram um número demasiado baixo para que a bilheteria pagasse os custos internacionais da peça - impossibilitou, infelizmente, a realização da versão brasileira de $O$ Balcão em Nova Iorque. Mas os aspectos do tratamento visual das fotografias apresentadas em The Balcony (a photo portfolio) fizeram que o ensaio fosse publicado em Performance. Esta publicação foi uma primeira e importante etapa para o desenvolvimento público da fotografia de Alair Gomes, que encontraria ainda outras formas de publicações.

\section{Publicação como arte contemporânea}

Entre as transformações discursivas e os materiais do campo da arte nas décadas de 1960 e 1970, novas concepções, estratégias, procedimentos e formatos foram sendo utilizados pelos artistas em 
atualizações sobre o que poderia ser considerado um trabalho de arte. Entre eles, podemos destacar publicações de artistas, por exemplo trabalhos artísticos realizados pela montagem de uma grande quantidade de imagens fotográficas exibidas por várias maneiras. As publicações de artistas, como livros, portfólios, panfletos e fanzines, bem como a intervenção artística realizada em jornais, revistas, cartazes, correspondências (na arte postal), entre outros, estabeleceram novos contornos para as categorias artísticas tradicionais, como a pintura, a escultura e até mesmo a gravura. A exploração do formato, do design e da tipografia de revistas e livros revelam, segundo Gwen Allen, a experimentação dos artistas com a "materialidade da linguagem e impressão, enfatizando a tactilidade e a interatividade da revista, e pondo em primeiro plano a ação de leitura e a manualidade da página" ${ }^{8}$. Com isso, a publicação recebeu um grande interesse dos artistas, relacionado principalmente com as transformações tecnológicas e o acesso facilitado aos meios de reprodução. O debate em torno da reprodutibilidade do meio, presente já nos trabalhos de Walter Benjamin dos anos 1930, receberia na década de 1960 grandes contribuições com os trabalhos de Marshall McLuhan.

Dentro desse disputado território, podemos citar as novas estratégias que os artistas adotaram enquanto práticas artísticas e formas/ formatos de trabalho, tais como o uso da fotografia e do suporte impresso. Diversos artistas fizeram uso da publicação como uma investigação artística, como os trabalhos de Edward Ruscha. Em livros como Twentysix Gasoline Stations (1963) e Every Building on the Sunset Strip (1966), encontram-se os recursos do mass producted product como um ataque à unicidade do objeto de arte. Tais noções também podem ser vistas na maneira como o uso da fotografia em larga escala se transformou em uma referência para que as ditas noções fossem pensadas no âmbito da arte. Diferentemente da noção do livro de artista, em uma produção artesanal, com uma edição única ou bastante limitada, a proposta de Ruscha é fazer um objeto de produção em massa9. Todo esse cenário não passou despercebido por Alair Gomes que, em um texto da década de 1970, intitulado "Arte, Ciência, Tecnologia" relata que:

em grande parte a explosão do inventivo artístico na segunda metade do nosso século [foi] devida exatamente ao encontro da arte com a tecnologia e a ciência. (...) Só a partir dos últimos anos, com a tardia mas total aceitação da fotografia nos grandes circuitos internacionais da arte, tem-se generalizado e expandido o conhecimento do impacto provocado pela fotografia, desde seu aparecimento, sobre as demais artes visuais. ${ }^{10}$

\section{André Pitol}

"Ask me to send these photos to you": a produção artística de Alair Gomes nos Estados Unidos.

8. ALLEN, Gwen. Artists' magazines: an alternative space for art. Cambrigde, MA. The MIT Press, 2011, p. 6. Tradução minha.

9. BURY, Stephen. Artist's books: the book as a work of art, 1963-1995. Aldershot: Scolar, 1995.

10. GOMES, Alair. Breve informe sobre arte, ciência, tecnologia, 1975. Localizado na Fundação Biblioteca Nacional - Brasil. Arquivo Alair Gomes. Não paginado. Texto datilografado. 
O texto do qual o excerto anterior foi destacado, no qual Alair Gomes evidencia seu interesse pelas experimentações com a fotografia e o suporte impresso como arte, foi escrito em 1975, ou seja, concomitantemente ao seu segundo trabalho fotográfico publicado nos Estados Unidos, a sua participação no Artists Almanac. Esse movimento teórico-prático evidencia um interesse, no mínimo, duplo pela atividade artística.

O projeto de uma communal publication foi idealizado pelo artista alemão Uli Boege em Nova Iorque e contou com a participação de muitos artistas e fotógrafos. Tendo como proposta geral do livro um desenho de uma parede de tijolos desenhado por Boege, o desafio era que todos os artistas que desejassem participar da publicação teriam que incorporar aquele padrão gráfico a seus trabalhos. Todos os que fizeram o proposto receberam uma página para a publicação e um exemplar gratuito do almanaque. Os trabalhos foram realizados nos mais diversos meios compatíveis com o suporte bidimensional - desenhos, colagens, assemblagens etc.

Fig. 3

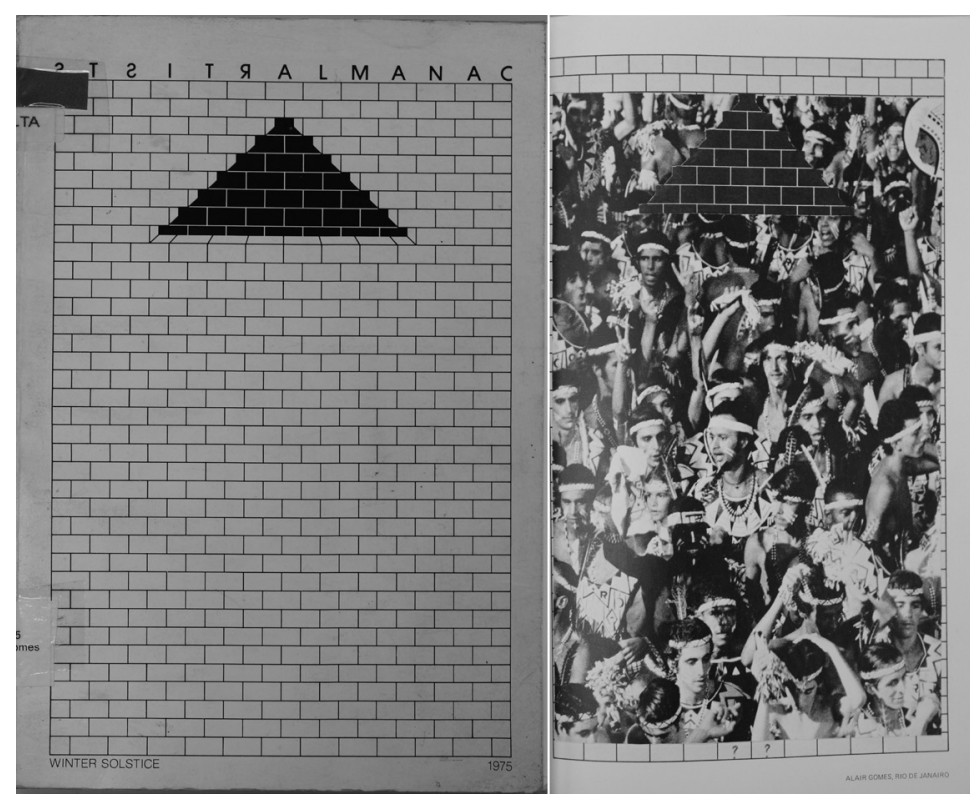

A proposta de Alair Gomes foi uma fotografia do bloco de carnaval do Rio de Janeiro Cacique de Ramos, onde os participantes se fantasiam de índios, segundo a tradição do grupo. A imagem ficou dentro dos limites da parede, conforme a sugestão de Boege. Ela cobre quase toda a superfície de tijolos, apenas deixando à vista duas colunas de tijolos na parte superior da página e uma coluna na parte inferior, além de uma fina parte da parede de cada um dos lados da fotografia. O resultado da colagem fotográfica de carnaval sobre 
a parede de tijolos gerou uma composição de elementos visuais que se confundem uns aos outros - a imprecisão (ausência de nitidez) da imagem em registrar os foliões, as manchas de seus corpos em movimento no carnaval aproximam-se do padrão de linhas perpendiculares pretas com áreas brancas da parede.

O carnaval é também um dos principais temas utilizados por Alair Gomes e, como é possível perceber na publicação de Artists Almanac, a proposta do fotógrafo aproximou o tema dos aspectos de publicação de arte do período, na qual artistas utilizam o suporte impresso como espaço para a produção e circulação de seus trabalhos. Podemos recordar o contato com Quentin Fiore, no qual vários temas são tratados por ambos - entre os quais o carnaval - em uma correspondência que durou de 1969 a 1984. Vários são os momentos em que o designer norte-americano comenta ter folheado o material fotográfico de Alair Gomes que havia levado do Brasil para os Estados Unidos, como "as fotos das lojas de caixões (...) aquelas que nós vimos no caminho do ritual de macumba" ${ }^{11}$, além das inúmeras imagens de carnaval.

Seu trabalho, assim como o carnaval, é uma atividade coletiva, é um objeto múltiplo ou um múltiplo gráfico que difere do livro, da predominância do livro de artista como objeto único. Tal defesa, é preciso dizer, já estava presente quando Alair Gomes publicou o texto "O livro, hoje" na Shell em revista em 1971, no qual defende o suporte impresso como lócus da produção artística, propondo uma breve história do livro e discutindo o seu uso em trabalhos de artistas brasileiros. O texto gira em torno da inquietação a respeito dos meios de comunicação e, especialmente, a discussão em torno do futuro do livro, apontando três transformações marcantes que afetaram o livro no contexto contemporâneo da comunicação de massa: a impregnação do livro pela imagem; a fragmentação serializada em fascículos de jornaleiro, feita também com o predomínio da imagem e a inclusão do livro na categoria mixed-media. As publicações de artista, dessa forma, foram decisivas para a demarcação desse objeto como trabalho de arte, tornando-se possível, como aponta o fotógrafo, "fazer construções ou montagens inventivas com fotos, não só por iniciativa dos fotógrafos com suas próprias imagens, mas também de outras pessoas com imagens de fotógrafos diferentes" ${ }^{12}$.

\section{A Gay essay in the tropics}

A criação de fotografias a partir de imagens do carnaval carioca não se limitou à página de Artists Almanac. Pelo contrário, essa temática
André Pitol

"Ask me to send these photos

to you": a produção artística de Alair Gomes nos Estados Unidos.

11. Carta de Quentin Fiore para Alair Gomes, 24 nov. 1969. Localizada na Fundação Biblioteca Nacional - Brasil. Arquivo Alair Gomes. Não paginado. Texto datilografado.

12. GOMES, Alair. Reflexões críticas e sinceras sobre a fotografia [1976]. Revista ZUM, São Paulo, n. 6, abr. 2014. Não paginado. 
foi uma constante em grande parte de sua produção e isso não será

13. GREEN, James. Além do carnaval: a homossexualidade masculina no Brasil do século XX. São Paulo: Unesp, 2000.

14. O National Endowment for the Arts é uma agência independente do governo norte-americano que financia projetos aprovados no campo das artes: teatro, cinema, música e literatura. diferente nos trabalhos publicados nos Estados Unidos. Em 1979, o fotógrafo realiza o ensaio intitulado The Carnival in Rio: a photo essay, no jornal Gay Sunshine: a Journal of Gay Liberation, em um número especial dedicado ao Brasil.

Diferentemente do trabalho anterior, no qual vimos que a imagem do grupo Cacique de Ramos foi trabalhada nos termos de uma montagem que seguisse o mote da revista de artista, percebe-se nesse caso o carnaval posto com o campo da sexualidade, ou seja, recebendo uma nova camada de sentido a ser trabalhado na produção do fotógrafo. A articulação entre carnaval e sexualidade tem na própria década de 1970 um momento de intensificação. O historiador James Green, por exemplo, aponta a importância que a comunidade gay teve ao se apropriar do carnaval carioca, em um processo longo e árduo, mas que consolidou uma nova identidade da subcultura homossexual no Rio de Janeiro e em São Paulo no final da década de 1970. Essa identidade relacionava-se principalmente à performance do corpo como inversão das relações dominantes de gênero e sexualidade, ou mais do que isso, um fenômeno interseccionado às tensões sociais arraigadas na sociedade brasileira ${ }^{13}$.

Essas reconstruções de identidades e sexualidades também estiveram ligadas à formação de um jornalismo independente e de uma imprensa alternativa gay como presença crítica ao presente histórico e como forma de resistência, principalmente no desenvolvimento dos movimentos sociais em reivindicação pela democracia durante o regime militar. No caso do Rio de Janeiro, jornais como O Snob, Já, Terceira Força, Vagalume, Gente Gay, Subúrbio à Noite, O Bem, O Show, Charme, O Pelicano, Le Carrilon, Le Femme, Centauro, Darling, O Grupo, La Saison, entre outros, além do caso mais conhecido, que é O Lampião da Esquina, focalizavam tal questão. O caso de Gente Gay, apenas por seu título, sugere a atualização dos termos de afiliação identitária e informações esparsas sobre o surgimento e o crescimento do movimento internacional de gays e lésbicas.

Um exemplo importante dessas relações entre imprensa e movimento gay naquele período - e o modo como essas relações estão ligadas à produção fotográfica que Alair Gomes realizou nos Estados Unidos - foi a viagem que Winston Leyland, o editor da Gay Sunshine Press, sediada em São Francisco, fez em 1977 para a América Latina. A partir de um prêmio concedido pela National Endownment for the Arts ${ }^{14}$ para a publicação de uma antologia de literatura gay latino-americana, Leyland reuniu material de escritores e artistas que deu origem ao livro Now the Volcano: an anthology of latin american gay literature, 
publicado em 1979 com uma seleção de autores de México, Colômbia e Brasil. Em 1983, ainda foi produzida mais uma antologia com o recorte latino-americano - My deep dark pain is love: a collection of Latin American Gay Fiction -, com uma seleção de trabalhos dos autores da Argentina, México, Cuba, Chile e Brasil.

A grande quantidade de material da pesquisa permitiu que, além das antologias, o editor produzisse uma edição monográfica de Gay Sunshine sobre o Brasil. Entre os autores brasileiros traduzidos e publicados estão: Gasparino Damata, Darcy Penteado, Caio Fernando Abreu, João Silvério Trevisan, Aguinaldo Silva, Ediberto Coutinho ${ }^{15}$. A parte dedicada ao Brasil conta ainda com os textos "Os entendidos: a vida da classe média gay em São Paulo”, do sociólogo norte-americano Frederick L. Whitman, e "Homossexualidade e a Inquisição no Brasil: 1591-92”, de Stephen W. Foster.

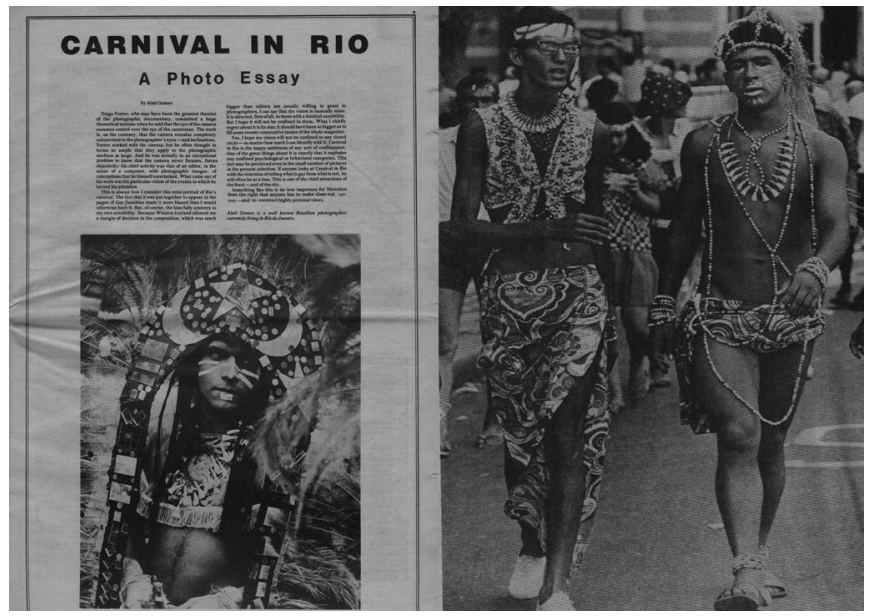

The Carnival in Rio: a photo essay é o único trabalho visual parte dessa edição. Ao publicar um ensaio sobre o carnaval carioca, o fotógrafo apresenta escolhas pessoais de viabilização do trabalho artístico, assim como evidencia os vínculos entre a imprensa e os movimentos de liberação gay norte-americanos e brasileiros. Nota-se que, enquanto na antologia Now the Volcano os artistas visuais escolhidos publicaram desenhos, gravuras ou ilustrações de pinturas, foi a fotografia a escolhida para a edição especial de Gay Sunhine.

O ensaio de Alair Gomes tem início já na capa do jornal, na qual se vê um retrato de um rapaz coberto em um cocar indígena e um colar de correntes. Depois da capa, segue outra fotografia, também individual, e na abertura do ensaio outro retrato de mais um participante

\section{André Pitol}

"Ask me to send these photos to you": a produção artística de Alair Gomes nos Estados Unidos.

15. Do conjunto descrito, Gasparino Damata, Darcy Penteado Itambém artista plástico), João Silvério Trevisan e Aguinaldo Silva, além do crítico de cinema Jean-Claude Bernadet, também podemos citar o antropólogo Peter Fry e os jornalistas Adão Costa e Clóvis Marques que fizeram parte da formação do jornal 0 Lampião da Esquina, em 1978.

Fig. 4

Alair Gomes, The Carnival in Rio: a photo essay, 1979. 
do carnaval, juntamente com um breve texto escrito pelo próprio Alair Gomes $^{16}$. Depois dessas duas imagens, seguem mais doze fotografias,

16. No texto, intitulado originalmente Carnival in Rio: A feast for gay eyes - and more, o fotógrafo relaciona alguns dos procedimentos de montagem fotográfica usados no ensaio com os procedimentos cinematográficos de

montagem de imagens documentais do cotidiano do russo Dziga Vertov. Uma visão particular entre a edição e a composição de imagens fotográficas é a forma que Alair Gomes encontra para se referir ao assunto. Alair aponta que a sua fotografia se relaciona com o cinema apenas na medida em que arranja um conjunto amplo de imagens de um mesmo tema segundo determinadas sequências, sem movimento.

Fig. 5

Alair Gomes, The Carnival in Rio: a photo essay, 1979. divididas em três grupos de quatro fotografias, dispostas duas
seis páginas, totalizando um ensaio com quatorze imagens.

Nas quatro primeiras e nas quatro últimas imagens, é possível notar o vestuário e as fantasias, assim como os adereços utilizados pelos foliões: índios, bebês e uma diversidade de montagens possíveis com acessórios, como colares, tecidos e adereços. Alguns deles olham para a câmera, percebendo a existência do fotógrafo, enquanto outros parecem ter sido fotografados distraídos em suas atividades, andando pela rua, conversando, pulando o carnaval. Já as quatro imagens dispostas na parte central do ensaio particularizam-se do conjunto por serem retratos e privilegiarem o rosto de quatro participantes do carnaval de rua, como o de um rapaz negro que, com um colar e um cocar, demonstra consciência plena da presença do fotógrafo em meio à multidão. Assim, as imagens nas páginas podem ser agrupadas em duas partes: um grupo de oito fotografias de homens, alguns sozinhos e outros em duplas, no qual é possível visualizar todas as fantasias que vestem, e outro grupo de quatro retratos, já que a aproximação da câmera é direcionada para os rostos dos rapazes.

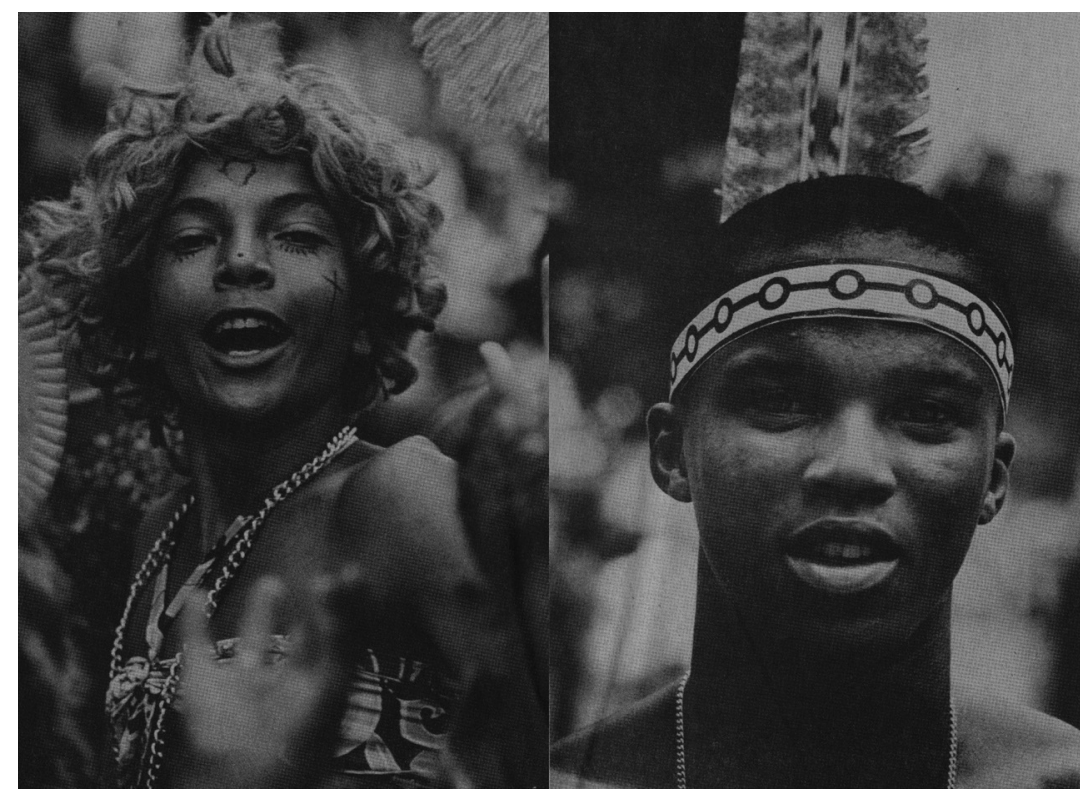

O formato tabloide do jornal, medindo $44,5 \mathrm{~cm}$ de altura por $28,5 \mathrm{~cm}$ de largura, permitiu que The Carnival in Rio recebesse significativo destaque em cada uma das páginas. O tamanho também foi um 
elemento crucial do processo de montagem do ensaio fotográfico pois, dispostas as imagens duas as duas, é o intervalo entre elas, ou ainda o espaço de passagem de uma página à outra, que produz as relações de sequencialidade do trabalho. Assim, a simples coletânea de um grupo de imagens em torno de um mesmo assunto não bastava, era preciso que essa coletânea também estivesse submetida a uma estruturação, a uma sequência estruturada. A discussão em destaque até o momento nos mostrou como o suporte impresso e a montagem fotográfica salientavam o sentido de ensaio fotográfico para Alair Gomes. Esta prática estava inteiramente relacionada às discussões sobre os modos de desenvolvimento do trabalho artístico e as modificações introduzidas no campo da fotografia, como é possível perceber no seu posicionamento para com aquela imensa obra que ali se constituía. A organização de uma coletânea de imagens fazia que "cada uma delas mostra[sse] uma certa novidade, um certo aspecto novo" ${ }^{17}$, como aponta o próprio fotógrafo, acionando o elemento narrativo do trabalho.

Essa discussão está intimamente ligada ao uso de novos materiais na produção artística, como a reconfiguração que a fotografia trouxe ao campo artístico. A ideia de reprodutibilidade técnica, reconhecida pelo texto de Walter Benjamin, repercutiu a partir dos anos de 1960 em autores como McLuhan, a respeito do impacto que as imagens técnicas tinham sobre a percepção da sociedade. A possibilidade infinita de cópias de um mesmo objeto - a impressão de um jornal - e o trabalho de arte como um objeto facilmente transportável são elementos encontrados nos trabalhos de Alair Gomes. Verifica-se também que essa experiência do artista relaciona-se a aspectos da comunidade gay em nível local e internacional, em uma mudança histórica naquele momento, envolvendo a interação entre personagens, grupos locais e processos mais amplos, com a expansão da imprensa gay norte-americana para um público em massa, transformação que se consolida na década de 1980. The Carnival in rio: a photo essay marcou a aproximação de Alair Gomes com as publicações gays norte-americanas, lócus que marcará ainda os últimos trabalhos do fotógrafo nos Estados Unidos encontrados até o momento.

\section{Lets talk about nudes}

A análise do trabalho anterior salientou que a presença do corpo é parte da produção fotográfica de Alair Gomes, porém não constitui sua totalidade. A organização sequencial da imagem fotográfica estabelece relações visuais com o suporte impresso da publicação e faz dela
André Pitol

"Ask me to send these photos to you": a produção artística de Alair Gomes nos Estados Unidos.

17. PAIVA, Joaquim. Entrevista com Alair Gomes, 19 jul. 1983. Localizado no Cento de Documentação FUNARTE, Rio de Janeiro (RJ). Não paginado. Texto datilografado. Uma versão encontra-se em JOAQUIM Paiva entrevista Alair Gomes, 1983: pela primeira vez publicado em português. Revista ZUM, São

Paulo, n. 6, abr. 2014. Não paginado. Disponível em: <https://goo.gl/nhRc6B>. Acesso em: 24 nov. 2017. 

das participações que o fotógrafo fez na seção "Portfolio", da revista

18. Surgida como jornal em Los Angeles em 1967, The Advocate é uma das principais revistas de grande circulação sobre temas gays nos Estados Unidos. Enquanto ela manteve as suas características originais, acompanhando o cenário político, social, de luta e conquistas do movimento gay, em 1984 foi criada a Advocate MEN, que se concentrou na publicação de ensaios nus masculinos.

19. As imagens publicadas nesta revista são as mais próximas dos trabalhos atualmente mais conhecidos de Alair Gomes. Os Beach Tryptics foram apresentados em diversas exposições, diferentes dos Serial Composition, que tiveram uma circulação bem mais reduzida.

20. GOMES, Alair. Fotografia sequencial, 1984. Localizado na Fundação Biblioteca Nacional - Brasil. Arquivo Alair Gomes. Não paginado. Texto datilografado. gay The Advocate, em 1983, e depois na seção "Showcase" de Advocate MEN, em $1987^{18}$, vemos que o conjunto de imagens escolhidas para cada uma das publicações apresenta diferentes maneiras de representar o corpo masculino jovem, particularmente o nu. A representação do nu é parte integrante das relações entre a sequência fotográfica e o corpo masculino propostas pelo fotógrafo e é também parte de um movimento temático maior da época, de reposicionamento do corpo na produção artística. A fotografia reconfigurou a arte em relação ao corpo, em uma mudança que fez uso do modelo de representação, enquanto imagem que se liga a um referente do mundo, especialmente a temas iconográficos como a figura humana, encontrados em diversos trabalhos da pop, da nova figuração e do hiper-realismo.

Com os trabalhos publicados em ambas as revistas, é possível ver que a relação do corpo na fotografia de Alair Gomes está ligada à intensa circulação de imagens masculinas, já existentes anteriormente, mas que nos anos 1980 apresenta uma expressiva reconfiguração, graças ao amplo crescimento da indústria de revistas e filmes gays norte-americanos. A ênfase no corpo masculino nu evidencia aqui um importante e pontual polo de interlocução com a fotografia de Alair Gomes.

O ensaio publicado no "Portfolio" da The Advocate edição 371, em julho de 1983, ocupa as duas páginas centrais da revista e é composto pela montagem de três trabalhos de Alair Gomes: um Beach Triptych e duas pequenas sequências fotográfica intituladas como Serial Composition, totalizando dez imagens ${ }^{19}$. O Beach Tryptich é composto por três imagens com torsos masculinos, isto é, rapazes em seus momentos de lazer e exercício nas praias cariocas. A semelhança entre a primeira e a terceira imagem do tríptico faz parte do processo de montagem proposto por Alair Gomes, no qual a "associação de fotos em uma sequência obedece aos critérios relativamente rígidos, ditados pelo valor plástico - composição e textura - das imagens" ${ }^{20}$.

As três imagens de Serial Composition opus 21, n. 2 poderiam ser confundidas, à primeira vista, com um Beach Triptych. Porém, se a quantidade de imagens entre as séries é compatível, outros elementos compositivos apontam para especificidades do trabalho. Em primeiro lugar, o ordenamento dos referentes fotografados difere essencialmente da montagem proposta nos trípticos. Lá o trabalho resultava da organização de três imagens advindas de momentos e corpos aleatórios e, no caso de Serial Composition, o que se vê são três imagens de um mesmo rapaz. A dinâmica presente entre as três fotografias ultrapassa 
a aproximação ou o distanciamento do modelo e do observador. A aproximação entre o modelo e a paisagem de fundo cria na imagem zonas topográficas claras e escuras.

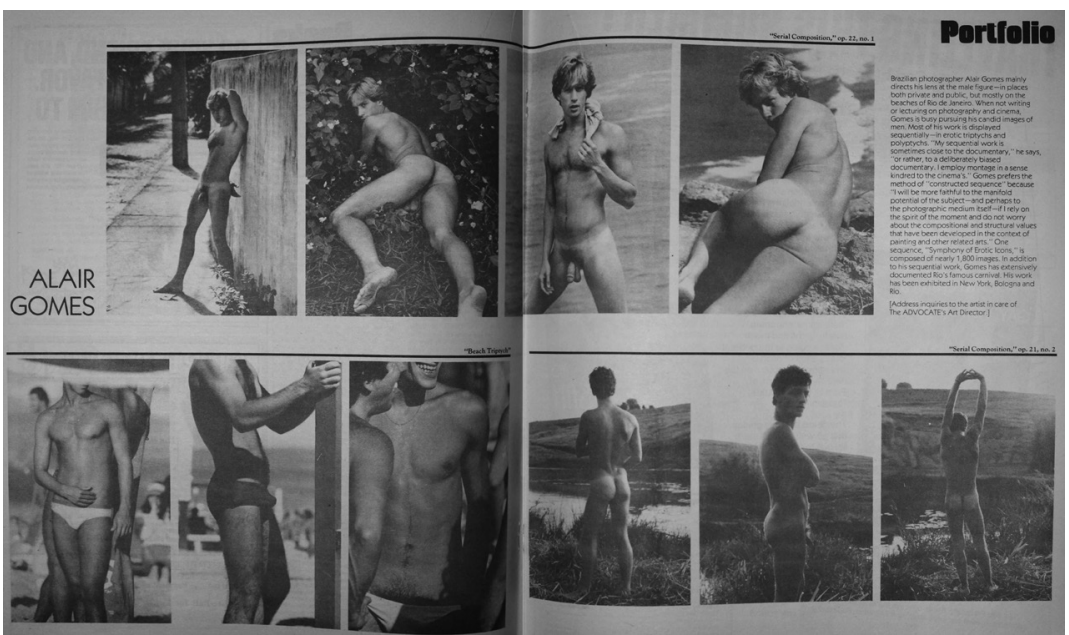

Nota-se nas quatro imagens de Serial Composition opus 22, n. 1 um mesmo procedimento de montagem utilizado. Na primeira e na terceira imagem, o modelo fotografado encontra-se em pé, levemente de perfil. Já na segunda e na quarta imagem, ele é posto de bruços, seja em uma composição vegetal, ou sobre uma pedra no litoral. Percebe-se aqui um uso prático para o que apontamos como uma narrativa sequencial. Em vez de organizar as imagens na ordem em que foram tiradas, o fotógrafo intercalava segmentos da sequência, montando um encadeamento visual para o conjunto fotográfico.

Essa descrição geral das imagens publicadas em "Portfolio", permite verificar que tal produção não se desvincula da relação entre imagem, suporte de publicação e circulação do trabalho, ou seja, uma temática fotográfica organizada para ocupar um suporte específico, em que a diagramação das sequências de imagens forma um conjunto visualmente equilibrado nas páginas. A concepção sequencial das imagens fotográficas sempre esteve diretamente relacionada ao seu posicionamento horizontal contíguo, uma imagem paralela à outra. Diversos são os escritos nos quais o fotógrafo discute a organização e o ordenamento das suas séries fotográficas sob o tema da "quantidade de imagens" em sua produção, especialmente o ensaio publicado em The Advocate.

Em uma entrevista concedida ao diplomata e fotógrafo Joaquim Paiva, realizada no mês da publicação de "Portfolio" - julho de 1983 -, Alair Gomes comenta a necessidade de construir um modo de pensar a

\section{André Pitol}

"Ask me to send these photos to you": a produção artística de Alair Gomes nos Estados Unidos.

Fig. 6

Alair Gomes, Portfolio - The Advocate, 1983. 
fotografia em relação às artes visuais, que "insistisse suficientemente na

ano 15

ก. 31

21. PAIVA, Op. cit.

22. Carta de Robert McQueen para Alair Gomes. 19 jun. 1986. Localizada na Fundação Biblioteca Nacional - Brasil.

Arquivo Alair Gomes. Não paginado. Texto datilografado.

23. Carta de Alair Gomes para Robert McQueen, 3 jun. 1986. Localizada na Fundação Biblioteca Nacional - Brasil.

Arquivo Alair Gomes. Não paginado. Texto datilografado.

24. Carta de Alair Gomes para Robert McQueen, 10 ago. 1986. Localizada na Fundação Biblioteca Nacional - Brasil.

Arquivo Alair Gomes. Não paginado. Texto datilografado. tomada de imagem fotográfica do jovem corpo masculino, simplesmente a abundância dessa imagem em situações diferentes (...) talvez esse acúmulo do número fantástico da imagem do jovem corpo masculino em situações diferentes”21. A relação entre a fotografia e a imagem do corpo masculino jovem na década de 1980 está conectada ao contexto norte-americano de reconfiguração da indústria pornô gay, cujas revistas envolvem projetos de montagens de narrativas para a apresentação dos corpos em cena. No caso de Alair Gomes, tal aproximação replicou a experiência em "Portfolio" da The Advocate, de modo que quatro anos depois daquela publicação, em 1987, o fotógrafo publica um pequeno ensaio na seção "Showcase" de Advocate MEN.

As negociações para esse segundo trabalho foram realizadas entre o Alair Gomes e o diretor de arte e o editor-chefe de The Advocate, Dennis Forbes e Robert McQueen, com quem o fotógrafo já havia trabalho na publicação de $1983^{22}$. Alair Gomes conheceu e manteve contato por um período pequeno com Forbes no Rio de Janeiro e, ao que parece, foi nessa oportunidade que ambos chegaram ao acordo de publicação de trabalhos fotográficos em Advocate $M E N^{23}$. O artista enviou onze impressões de nus frontais, declarando em carta que a montagem das imagens deveria seguir a ideia justamente de um showcase, em que a primeira imagem viria na página de abertura e as imagens dois e três estariam junto com um texto de apresentação e as imagens restantes nas páginas seguintes ${ }^{24}$.

A página inicial de "Showcase" seguiu a sua sugestão. Uma imagem única foi centralizada na página com um fundo gráfico abstrato, em tons de cinza, assim como a fotografia de um torso masculino, enquadrado sem a cabeça e sem as partes das pernas, estas se encontram abertas em espacate na areia, e as mãos vestem luvas de goleiro de futebol. A definição ressalta tanto as áreas claras quanto os pontos escuros.

A partir da primeira imagem, porém, as recomendações de Alair Gomes tomaram outros rumos. Vê-se que o "Showcase" de Advocate MEN foi disposto de uma maneira completamente diversa, com a mistura das imagens selecionadas e provenientes de séries como Beach, Beach Triptychs e outras de trabalhos como Symphony ou Opus 3, Adoremus e Fragments. O Beach Triptych é o único trabalho que permanece na ordem proposta pelo fotógrafo, enquanto os outros trabalhos partes de outros Beach Tryptich e também partes de Symphony of Erotic Icons ou de Adoremus, cenas de rapazes na praia ou no estúdio dentro do seu apartamento - foram publicados individualmente ou em duplas nas outras páginas da seção da revista. 


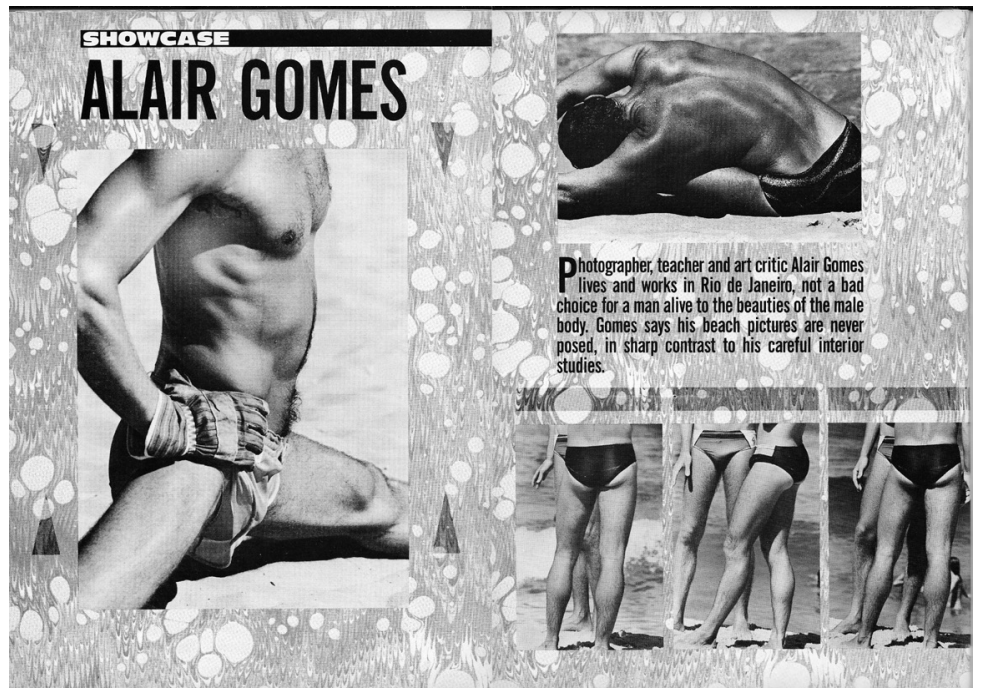

Com tal experiência, é possível notar as relações de sucesso e de tensão de uma publicação que envolvia não apenas o trabalho do fotógrafo, mas também a intervenção de outros profissionais do campo editorial. O ocorrido parece replicar um texto escrito por Alair Gomes em 1976, no qual ele aponta a dependência do artista perante outros atores do campo artístico, em que "o fotógrafo precisa sujeitar-se a editores, designers gráficos ou curadores [e onde] os critérios utilizados para organizar as fotos para uma publicação são em geral tão superficiais que impossibilitam a criação de um conjunto convincente" ${ }^{25}$.

Não objetivamos transformar a citação destacada, de um texto de 1976, em um prenúncio do que Alair Gomes realizaria nos anos 1980. A interpretação que se pode fazer é ver nela uma discussão presente em diversos momentos de sua produção e, principalmente, em que é possível verificar, para além de posição unidirecional, as ambivalências e o processo de compreensão daquilo que ele estava fazendo com a fotografia, um trabalho que envolvia uma "quantidade de imagens" em um suporte impresso. A ideia de sequência fotográfica de Alair Gomes acabou adquirindo, com isso, uma fluidez maior do que se imaginava, resultado de um trabalho contínuo com a fotografia, que se organizava tanto de modo serial maior quanto de versões enxutas, como nos trípticos. Tais relações estavam sujeitas às mais diferentes posições, como o próprio fotógrafo comentou:

o trabalho com imagens fotográficas em grande quantidade muitas vezes pode exigir que se desenvolva um novo tipo de atividade artística (...) com características próprias. Pode chegar a resultados que vão desde a narrativa até a livre associação - dirigida ou não -, e, também, pode assumir um caráter aleatório ${ }^{26}$.
120

\section{André Pitol}

“Ask me to send these photos

to you": a produção artística de Alair Gomes nos Estados Unidos.

Fig. 7

Alair Gomes, Showcase Advocate MEN, 1987.

25. GOMES, Alair. Reflexões críticas e sinceras sobre a fotografia [1976]. Revista ZUM, São Paulo, n. 6, abr. 2014. Não paginado.

26. Ibidem 

momentos diferentes, em publicações norte-americanas direcionadas principalmente ao público gay, possibilitam-nos ainda compreender os espaços de circulação da imagem considerada pornográfica no Brasil e nos Estados Unidos. A complexidade da discussão e da circulação de Alair Gomes encontrou espaço em um momento em que os aspectos da sua produção podem ser associados a outros fatores, de ordem pessoal e religiosa bem como as diversas maneiras como ele se dirige ao próprio trabalho. Enfim, considerar ou não parte de sua produção pornográfica não estava apartado dos debates sobre a representação do corpo e da sexualidade ocorridos nos Estados Unidos, em que sua fotografia foi primeiramente trazida ao público. O que se tem é que a variedade de aspectos que caracterizam especificamente as publicações em The Advocate (1983) e Advocate MEN (1986) pode ser tida, de modo geral, como um conceito de imagem gay.

\section{Uma produção homoerótica?}

Como pudemos perceber com a discussão aqui realizada, desde o momento em que tomou a fotografia como uma possibilidade efetiva de desenvolvimento artístico contínuo, Alair Gomes passou a explorá-la, de uma perspectiva crítica, debatendo o seu papel dentro do campo das artes. A construção de narrativas fotográficas pela montagem sequencial de inúmeras imagens esteve intimamente relacionada às soluções materiais que envolveram pensar a publicação de revistas, jornais e livros como suportes para sua produção artística.

A publicação de ensaios fotográficos em suportes de pequeno ou grande circulação, impressos nos Estados Unidos, são aspectos centrais dessa sua produção artística nas décadas de 1970 e 1980 e fez deles uma forma alternativa central de substituição do espaço privilegiado do museu. A publicação de artista estabeleceu novos limites e contornos sobre as categorias artísticas. Uma multiplicidade de materiais, de formatos e de procedimentos artísticos passou ao primeiro plano nos debates sobre o que poderia ser considerado um trabalho de arte. Essa nova configuração do campo encontra espaço, por exemplo, em Artists Almanac, assim como também aparece no ensaio fotográfico realizado sobre a peça teatral O Balcão e publicado na revista Performance.

A reprodução em larga escala é também um aspecto comum aos ensaios de Alair Gomes, pois a reprodutibilidade da imagem fotográfica aliada à produção gráfica industrial gerou uma quantidade significativa de múltiplos impressos. Assim, o objeto impresso entendido como 
arte alterou significativamente a concepção de unicidade do trabalho de arte, contrastando com o livro-objeto e o livro-obra, conhecidos pela confecção artesanal de poucas edições ou ainda de exemplares únicos. Os ensaios publicados em Gay Sunshine, The Advocate e Advocate MEN - revistas de grande circulação voltadas para o público gay nos anos 1970 e 1980 - alcançaram uma abrangência nacional.

É preciso dizer também que a efemeridade, o tempo de desgaste e descarte da revista e do jornal fez que esse tipo de trabalho tivesse transitoriedade e temporalidade específicas, o que pode ser tido como um dos motivos dessa parte da produção de Alair Gomes ser totalmente desconhecida - ou pouco conhecida - pelos pesquisadores que estudam o fotógrafo ${ }^{27}$. Esse desconhecimento fez que até o momento a reconstrução historiográfica de sua trajetória artística fosse realizada principalmente a partir das exposições que o artista realizou.

Este trabalho buscou expor que Alair Gomes apresentou suas fotografias primeiros nos Estados Unidos e só depois no Brasil. Embora alguns de seus trabalhos mais conhecidos datem da metade dos anos 1960, a recepção de sua obra no território brasileiro ocorreu apenas na década de $1980^{28}$ por um nicho de amigos e em pequenas exposições, em sua maioria no Rio de Janeiro. Um dos motivos possíveis para essa condição seria ter vivido e produzido sob a ditadura militar ${ }^{29}$. Provavelmente, a temática erótica de parte de sua produção fotográfica não o favorecia para exibição naquele momento no país. Esses e outros motivos talvez tenham feito que o artista realizasse suas séries fotográficas de modo muito reservado e discreto e, por isso, não chegou a construir uma carreira artística. Só após sua morte, em 1992, sua obra começou a ser mais exibida em mais exposições, tanto no cenário artístico brasileiro quanto no internacional ${ }^{30}$.

A circulação de Alair Gomes nos Estados Unidos está ligada à sua trajetória profissional como professor e pesquisador no curso de pós-graduação do Instituto de Biofísica da Universidade do Brasil - atual Universidade Federal do Rio de Janeiro (UFRJ) - nas décadas de 1960 e 1970. As relações do fotógrafo com o instituto se dão nos aspectos institucionais por meio de acordos que o artista mantinha com as universidades e fundações estrangeiras, com destaque para o incentivo privado norte-americano. Deste, podemos citar a bolsa Guggenheim que Alair Gomes ganhou em 1962 na categoria de "História da Ciência e Tecnologia" e que permitiu a sua estadia no Departamento de Física na Universidade de Yale, em Connecticut, ou ainda a participação que fez na Quarta Conferência Internacional para a Unidade das Ciências, na cidade de Nova Iorque, em novembro de 1975, oportunidade na qual

\section{André Pitol}

"Ask me to send these photos

to you": a produção artística de Alair Gomes nos Estados Unidos.

27. 0 processo de reunião de cada uma das cinco revistas foi realizado por mim entre 2013 e 2016, as quais foram pouco a pouco localizadas e compradas em sebos de livros usados dispersos no Brasil e nos Estados Unidos. A descoberta exata dos trabalhos em cada umas das revistas também envolveu uma extensa pesquisa de documentação primária no Arquivo Alair Gomes, localizado na Fundação Biblioteca Nacional, no Rio de Janeiro e na biblioteca pessoal do fotógrafo, doada à Universidade Federal Fluminense (UFF). Agradeço a Luciana Muniz Sousa por toda a disponibilidade e ajuda na consulta aos arquivos de Alair Gomes.

28. Algumas exposições tanto individuais quanto coletivas como "As Artes no Shopping" (Rio de Janeiro, 1980), "Alair Gomes" (Rio de Janeiro, 1980), "Alair Gomes: fotografia sequencial" (Rio de Janeiro, 1984), "I Quadrienal de Fotografia do MAM" (São Paulo, 1984), “Arte em Papel” (Rio de Janeiro, 1987), entre outras.

29. Este argumento contrasta com um perfil público de Alair Gomes como pesquisador e professor do Instituto de Biofísica da Universidade do Brasil nas décadas de 1960 e 1970. A sua posição em um círculo universitário de classe média carioca fez que o artista tivesse ampla circulação em partes daquele circuito, publicando inúmeros textos científicos e artísticos em revistas e jornais e, em plena 

São Francisco, e deu origem ao ensaio fotográfico Glimpses of America:

ditadura, tivesse abertura para viajar para congressos científicos na Europa e nos Estados Unidos. Esse aspecto contraditório faz parte de sua trajetória e de seu lugar histórico e aos poucos vem sendo conhecido.

30. Algumas das exposições ocorridas no Brasil são: "Arte Erótica” (Rio de Janeiro, 1993), "Alair Gomes (in memorian)" (Rio de Janeiro, 1995), “I Bienal Internacional de Fotografia de Curitiba" (Curitiba, 1996), "Alair Gomes, fotógrafo" (São Paulo, 1999), "Corpus" (Rio de Janeiro, 2003), "Alair Gomes, um voyeur natural" (2008) e a “30 Bienal Internacional de Arte" (São Paulo, 2013). Das exposições internacionais: "Photographie Contemporaine au Brésil: Corpo\&Alma" (Paris, 1984), "Contemporary Brazilian Photography: a selection of photographs from the collection of Joaquim Paiva" (San Francisco, 1994), "Alair Gomes" (Paris, 2001), "A New Sentimental Journey" (Paris, 2009) e as mais recentes "Alair Gomes - Percursos" (São Paulo, 2015) e "Young Male: fotografias de Alair Gomes" (São Paulo, 2016), ambas em 2016.

Artigo recebido em 6 de março de 2017 e aceito em 9 de novembro de 2017. a sentimental journey, trabalho que, embora possua os Estados Unidos como tema da imagem, não circulou na época e nem recebeu montagens póstumas em exposições.

Mais do que uma vocação ou um desejo subjetivo pela fotografia que vinha desde a infância, o que se percebe é que foi o Instituto de Biofísica que possibilitou à Alair Gomes um contato contínuo com a fotografia, desde os anos 1960, espaço que permitiu a ele aperfeiçoar o aspecto técnico que poucos anos mais tarde utilizaria para a construção e a montagem de suas séries fotográficas. A concepção da fotografia como uma maneira de fixar o tempo em um espaço bidimensional esteve presente em diversos estudos e experimentos artísticos e em práticas científicas de laboratório. Esse argumento possibilita uma melhor compreensão acerca dos temas levados a cabo pela fortuna crítica sobre Alair Gomes, ainda que refém do que foi intitulado como pressuposto homoerótico.

Concluindo, a intensa relação de Alair Gomes com os Estados Unidos possibilitou ao fotógrafo situações, condições e formas de materializar seu trabalho artístico. Em uma nota encontrada no Arquivo Alair Gomes está um pedido do fotógrafo para que um amigo levasse a um outro conhecido norte-americano alguns de seus trabalhos: "Alair asked me to send these photos to you". A análise dos cinco trabalhos publicados em suportes impressos permitiu, espero, contribuir para o redimensionamento da posição ocupada por Alair Gomes na discussão sobre fotografia contemporânea.

Os elementos apresentados, como propomos aqui, apontam para o fato de que esse pressuposto homoerótico replicado pela crítica de arte sobre a produção de Alair Gomes é apenas uma das faces de uma obra fotográfica mais diversa e ainda não analisada de maneira intensa, a despeito de um certo interesse brasileiro e internacional. Posta em termos, propomos um percurso investigativo para a fotografia que busque a potência da produção de Alair Gomes para além do reconhecimento de um punctum bartheano na imagem de um pênis ereto.

André Pitol é pesquisador em artes, mestre em Artes Visuais na linha de pesquisa de História, Crítica e Teoria da Arte e bacharel em Artes Plásticas com habilitação em Gravura, ambos pela Escola de Comunicações e Artes da Universidade de São Paulo [USP]. Atualmente desenvolve projetos gráficos e editoriais para livros e outras publicações. 
